\title{
Heart Rate Variability in Dairy Cattle: Measurement and Time Domain Analysis
}

M. Minero, E. Canali, V. Ferrante, C.Carenzi.

M. Minero, DVM, E. Canali, DVM, V. Ferrante, DVM, C. Carenzi, DVM, Istituto di Zootecnica Veterinaria, Università degli Studi di Milano, Via Celoria, 10, 20133, Milano, Italy. 
The individual differences and the physiological state of animals determine their vulnerability to stress and cause different subjects to react in several ways to the same stressors (Porges, 1985). So, it is of particular interest, in intensive farm conditions, to identify those physiological characteristics which predispose animals to succeed or not in coping with a potentially stressful environment (Terlow et al, 1997).

It is known that central mechanisms take part in the modulation of challenge reactions and stress sensibility: both branches of the Autonomic Nervous System respond rapidly to central influences, but only an enhancement in sympathetic tone and changes in endocrine parameters have generally been associated with the stress response in farm animals (Broom and Johnson, 1993). Relatively little interest has been directed to the Parasympathetic role in defining stress, but there is some evidence that in mammals the vagal component of the Autonomic Nervous system plays a major role in regulating heart rate in response to stressors and could be considered a physiological marker of stress vulnerability (Hansen and von Borrell, 1998; Hopster and Blokhuis, 1994; Hull et al, 1990; Porges, 1995; Sgoifo et al., 1997). Cardiac vagal tone may be non invasively evaluated by analysing the Heart Rate Variability (HRV) which gives information about the sympathetic-parasympathetic autonomic balance (van Ravenswaaij-Arts et al, 1993). Porges (1995) proposed that the physiologic variability in heart rate should be considered a better indicator of the individual capacity to cope with the environment than simple heart rate and Hopster and Blokhuis in 1994 pointed out the importance of expanding knowledge of HRV in farm animals. HRV, which is the conventionally accepted term to describe variations of both instantaneous heart rate and interbeat intervals (Task Force of the ESC and the NASPE, 1996), has been quantified in several lines of human clinical research since 1965 when Hon and Lee noted that foetal distress was preceded by a reduction in HRV. Later in the $1980_{\text {s }}$ this parameter was confirmed to be a reliable predictor of life-threatening events in patients with cardiac disorders and it has only recently been 
1 investigated as a measure of physical and psychological strain (Task Force 2 of the ESC and the NASPE, 1996).

3 Most of the studies conducted on animals considered laboratory rodents, dogs and miniature swine as animal models for biomedical research while horses gained attention because of their predominant parasympathetic nervous activity at rest (de Jong et al, 2000; Kuwahara et al, 1999). Up to now studies on farm animals have been scarce probably due to the practical difficulties encountered performing reliable measures of HRV in field conditions. The first step in analysing HRV is actually to achieve reliable recordings of consecutive heart beats and this can be obtained by Holter monitoring the animals or recording every interbeat interval (Fig.1) with heart rate monitors suited to this purpose (Calvert, 1998). In cattle, the heart rate has been recorded during different procedures (Lay et al, 1992; Le Neindre, 1989) and Polar ${ }^{R}$ heart rate monitors were successfully validated for use with dairy cows (Hopster and Blokhuis, 1994). However in field conditions the presence of artifacts caused by movements of electrodes on the skin or muscle contraction could often impair the obtaining of beat to beat intervals suitable for HRV.

The variation in heart rate may then be evaluated in two ways: calculating mathematical indices in the time domain analysis or studying frequency specific oscillations of R-R intervals (in an ECG record, the duration of time between adjacent QRS complexes, Fig.1) in frequency domain analysis. The time domain variables give quantitative information on how much variability there is, moreover, various $\mathrm{R}-\mathrm{R}$ interval distribution histograms and Poincaré graphs give fairly accurate qualitative information on HRV at a glance (Calvert, 1998).

The aims of this research were: to develop standards of measurement for farm evaluation of HRV in dairy cattle and to assess HRV in a group of animals of the same gender and different age.

Heart Rate Variability (HRV) of 6 female calves, 6 heifers, 6 primiparous and 6 cows homogenous in age, with no clinical signs of cardiac diseases, was monitored. 
1 The animals were group stabled, according to age, in a deep litter system, and belonged to an intensive dairy farm near the city of Milan (Italy). The cows were fed unifeed ad libitum. Water was available ad libitum. HRV was measured using a non-invasive telemetric system (Polar Vantage NV) settled to record every interbeat interval. The system consisted in two special electrodes adapted for large animals (Horse Trainer) connected with a wire to a transmitter. The heart rate signal was transmitted to a wrist receiver and all the apparatus was attached to a girth belt. Positioning the girth belt just behind the scapula of the bovines, one of the two electrodes was placed on the cardiac area and the other one on the upper left thorax, just behind the scapula. All the animals were always handled by the same person and they were first well accustomed to the belt. When each recording session was completed, the belt was removed and the heart rate data were uploaded into a notebook for the analysis. HRV was recorded during different days, in the morning, each session lasting 15 minutes while animals were restrained in their usual pens, in self-tethering gates. For each animal, the indices were calculated in a time window of five minutes, chosen from the whole period of recording, because data to be compared should have the same duration, and five minutes seem to be an appropriate option for the time domain methods (van Ravenswaaij-Arts et al, 1993; Task Force of the ESC and the NASPE, 1996). HRV was assessed by calculation of indices based on statistical operations on R-R intervals (time domain analysis). The following heart rate variability indices measured in the time domain area and Poincaré graphs were calculated using the Polar ${ }^{R}$ software (Tab.1): SD, standard deviation of the R-R intervals; MAXMIN, difference between maximum and minimum R-R interval; RMSSD, root mean square of successive differences; Poincaré graph, in this graph successive R-R intervals are plotted against each other; INDA, in the Poincaré graph index $A$ is the diameter that is parallel with the diameter of the co-ordinate system. It represents the standard deviation of continuous long-term RR-interval variability; INDB, index B is transverse to index A, 
1 represents the standard deviation of instantaneous beat-to-beat RR-

2 interval; INDA/INDB, indexA:indexB ratio.

3 HRV indices in different classes of age were analysed by analysis of variance 4 ANOVA (SAS, 1985).

Abnormal waveforms in R-R intervals were found in the recordings referring to technical artifacts. Working with animals in field conditions, the poor contact between electrodes and skin and the movement of electrodes due to the presence of hair and of cutaneous muscles could have caused the presence of the artifacts as also reported in literature (Hopster and Blokhuis, 1994; de Vel, 1984). Nevertheless the equipment and the standards of measurement used obtained acceptable recordings of interbeat intervals with less than $5 \%$ of artifacts in every analysed interval, meeting the requirements of the ESC and the NASPE for the human clinical evaluation of HRV (Task Force of the ESC and the NASPE, 1996). To analyse HRV over longer periods of time ( $24 \mathrm{hrs}$ ), efforts should be made to further improve the accuracy of recording equipment and editing processes of the data because the presence of even few artifacts in the analysing data may lead to serious misinterpretations of results. In other research carried out in more controlled conditions, more sophisticated equipment which recorded data more accurately was used (de Jong et al, 2000; Kuwahara et al, 1999). However, the use of a non-invasive telemetric system is essential in farm conditions to give the researchers insight into Autonomic Nervous System control not accessible with restrictive, invasive procedures greatly influencing animal behaviour in that situation.

The Poincare plot of Fig.2 qualitatively illustrates the HRV of one of the cows. Sudden changes in heart beat are shown as points far from the others. Low levels of HRV are represented by a narrow ellipse drawn around the area covered by the points while a higher HRV would give larger ellipses.

Table 1 shows the values of the time domain indices observed in the animals grouped by age. The level of HRV presented a great individual variability, evidenced by high standard deviations, suggesting that in further 
1 studies it would be best to perform intra-individual comparisons of indices during different challenges and breeding conditions. The analysis of time domain indices of the heart period data indicated that the HRV of the observed animals decreased, with no statistical difference (INDA and MAXMIN $\mathrm{P}=0.09$ ), with advancing age. This pattern is consistent with the studies conducted in humans where the amount of HRV is influenced by maturational factors. In adults an attenuation of respiratory sinus arrhythmia can be observed while the decline of HRV starts in childhood (van Ravenswaaij-Arts et al, 1993). Considering the effect of age on the HRV of the animals in this study, larger normal standards of HRV for different ages, sexes and environment. As already pointed out in human clinical research, this uncertain knowledge limits the interpretation possibilities of HRV, especially when comparing data from different subjects and could lead to incorrect explanation of the results (Task Force of the ESC and the NASPE, 1996). The studies carried out up to now in order to evaluate the possibility of using HRV as a stress indicator in animals have shown controversial results and this was probably due to the use of animals of different ages (Forde and Marchant, 1999; de Jong et al, 2000). The results of this research indicate that HRV is an interesting and potentially reliable indicator for the assessment of welfare at farm level. Further studies are needed and should consider both intra-individual differences in HRV of animals exposed to various procedures and large population basal recordings to better determine the predictive value of HRV in the identification of individual vulnerability to stress. 


\section{ACKNOWLEDGMENTS}

We are grateful to Dr. M. Bruni for giving access to his animals and facilities and to Dr. A. Loaldi for helping in collecting data. 


\section{REFERENCES}

BROOM, D.M. \& JOHNSON, K.G. (1993). Stress and Animal Welfare. London, Chapman \& Hall pp. 92-107.

CALVERT, C.A. (1998). Heart Rate Variability. Veterinary Clinics of North America: Small Animals Practice 28 (6), 1409-1427.

FORDE, R.M. \& Marchant, J.N. (1999). Heart Rate Variability: a novel noninvasive means of assessing fear responses in animals ?. Proceedings of the $33^{\text {rd }}$ congress of the ISAE, Lillehammer, Norway.

HANSEN, S. \& VON BORRELL, E. (1998). Impact of pig grouping on sympatho-vagal balance as measured by heart rate variability. Proceedings of the $32^{\text {nd }}$ congress of the ISAE, Clermont-Ferrand, France.

HON, E.H. \& LEE, S.T. (1965). Electronic evaluations of the foetal heart rate patterns preceding foetal death: further observations. American Journal of Obstetrics and Gynaecology 87, 814-826.

HOPSTER, H. \& BLOKHUIS, H.J. (1994). Validation of a heart-rate monitor for measuring a stress response in dairy cows. Canadian Journal of Animal Science 74, 465-474.

HULL, S.S., EVANS, A.R., VANOLI, E., ADAMSON, P.B., STRAMBA-BADIALE, D.E., AlBERT, D.E., FOREMAN, R.D. AND SCHWARTZ, P. J. (1990). Heart rate variability before and after myocardial infarction in conscious dogs at high and low risk of sudden death. Journal of American College of Cardiology 16, 678-685. 
DE JONG, I.C., SGOIFO, A., LAMBOOIJ, E., KORTE, S.M., BLOCKHUIS, H.J. AND KOOLHAAS, J.M. (2000). Effects of social stress on heart rate variability in growing pigs. Canadian Journal of Animal Science 80, 273280.

KUWAHARA, M., HIRAGA, A., KAI, M., TSUBONE, H. AND SUGANO, S. (1999). Influence of training on autonomic nervous function in horses: evaluation by power spectral analysis of heart rate variability. Equine Exercise Physiology 30, Suppl., 178-180.

LAY, D.C., JR, FRIEND, T.H., RANDEL, R.D., BOWERS, C.L., GRISSOM, K.K. AND JENKINS, O.C. (1992). Behavioural and physiological effects of freeze or hot-iron branding on crossbred cattle. Journal of Animal Science 70, 330336.

LE NEINDRE, P. (1989). Influence of rearing condition and breed on social behaviour and activity of cattle in novel environments. Applied Animal Behavioural Science 23, 129-140.

PORGES, S.W., (1985). Spontaneous Oscillations in Heart Rate: Potential Index of Stress in Moberg G.P. (ed.) Animal Stress. Bethesda, American Physiological Society pp. 97-111.

PORGES, S.W., (1995). Cardiac vagal tone: A physiological index of stress. Neurosciences and Biobehavioral Reviews 19 (2), 225-233.

VAN RAVENSWAAIJ, C.M.A., KOLLÉE, L.A.A., HOPMAN, J.C.W., STOELINGA, G.B.A. AND VAN GEIJN, H.P., (1993). Heart Rate Variability. Annals of Internal Medicine 118 (6), 437-445.

SAS (1985). User's Guide. Cary, Sas Institute Inc. 
SGOIFO, A., DE BOER, S.F., WESTENBROEK, C., MAES, F.W., BELDHUIS, H., SUZUKI, T. AND KOOLHAAS, J.M. (1997). Incidence of arrythmias and heart rate variability in wild-type rats exposed to social stress. American Journal of Physiology 273, H1754-H1760.

TASK FORCE OF THE EUROPEAN SOCIETY OF CARDIOLOGY AND THE NORTH AMERICAN SOCIETY OF PACING AND ELECTROPHYSIOLOGY, (1996). Heart Rate Variability: Standards of Measurement, Physiological Interpretation and Clinical Use. Circulation 93 (5), 1043-1065.

TERLOW, E.M.C., SCHOUTEN, W.G.P. AND LADEWIG, J, (1997). Physiology in Appleby M.C. and Hughes B.O. (eds.) Animal Welfare. Wallingford, CAB International pp. 143-158.

DE VEL, O.V., (1984). R-wave detection in the presence of muscle artifacts. IEEE Transaction on Biomedical Engineering 31(11), 715-717. 


\begin{tabular}{|c|c|c|c|c|c|c|}
\hline Indices & Description & Significance & Calves & Heifers & Primiparous & Cows \\
\hline SD & Stdev of RR intervals & Estimate of overall HRV & $127.3 \pm 187.2$ & $51.4 \pm 21.7$ & $29.2 \pm 9.6$ & $33.1 \pm 11.4$ \\
\hline INDA & $\begin{array}{l}\text { Longer diameter of the Poincare } \\
\text { graph }\end{array}$ & Long term HRV, sympathetic activity & $141 \pm 226.9$ & $68.8 \pm 29.9$ & $39.8 \pm 13$ & $44.9 \pm 16.3$ \\
\hline INDB & $\begin{array}{l}\text { Shorter diameter of the Poincare } \\
\text { graph }\end{array}$ & $\begin{array}{l}\text { Short term HRV, parasympathetic } \\
\text { activity }\end{array}$ & $79.1 \pm 152.2$ & $20.8 \pm 10.2$ & $10.4 \pm 5$ & $11 \pm 4.3$ \\
\hline MAXMIN & $\begin{array}{l}\text { Difference between max and } \min \mathrm{RR} \\
\text { intervals }\end{array}$ & $\begin{array}{l}\text { All components contributing to } \\
\text { variability }\end{array}$ & $443.5 \pm 326.6$ & $343.5 \pm 229$ & $208.7 \pm 78.1$ & $246.5 \pm 126.1$ \\
\hline RMSSD & $\begin{array}{l}\text { Root mean square of successive } \\
\text { differences }\end{array}$ & $\begin{array}{l}\text { Estimate of short term components of } \\
\text { HRV }\end{array}$ & $112.2 \pm 215$ & $29.8 \pm 14.9$ & $14.8 \pm 7$ & $15.7 \pm 6.2$ \\
\hline INDA/INDB & IndexA/indexB ratio & Sympatho-vagal balance & $3.8 \pm 3.6$ & $3.6 \pm 1.6$ & $4.2 \pm 1.3$ & $4.6 \pm 2.1$ \\
\hline
\end{tabular}

Tab.1: Mean (stdev) HRV indices in different ages. 


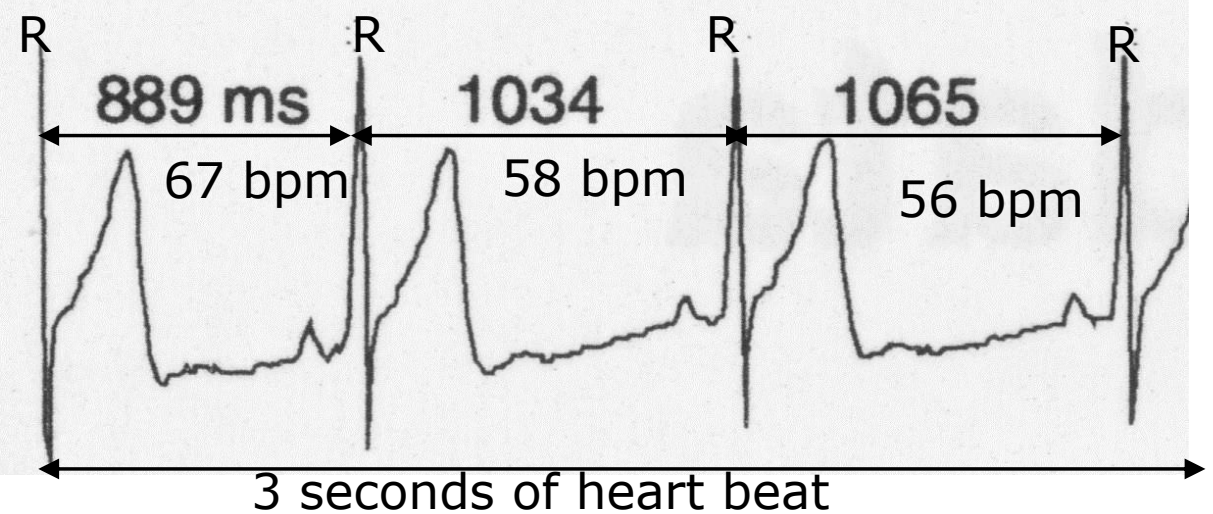

Fig.1. Measure of the R-R interval changes in heart rate 


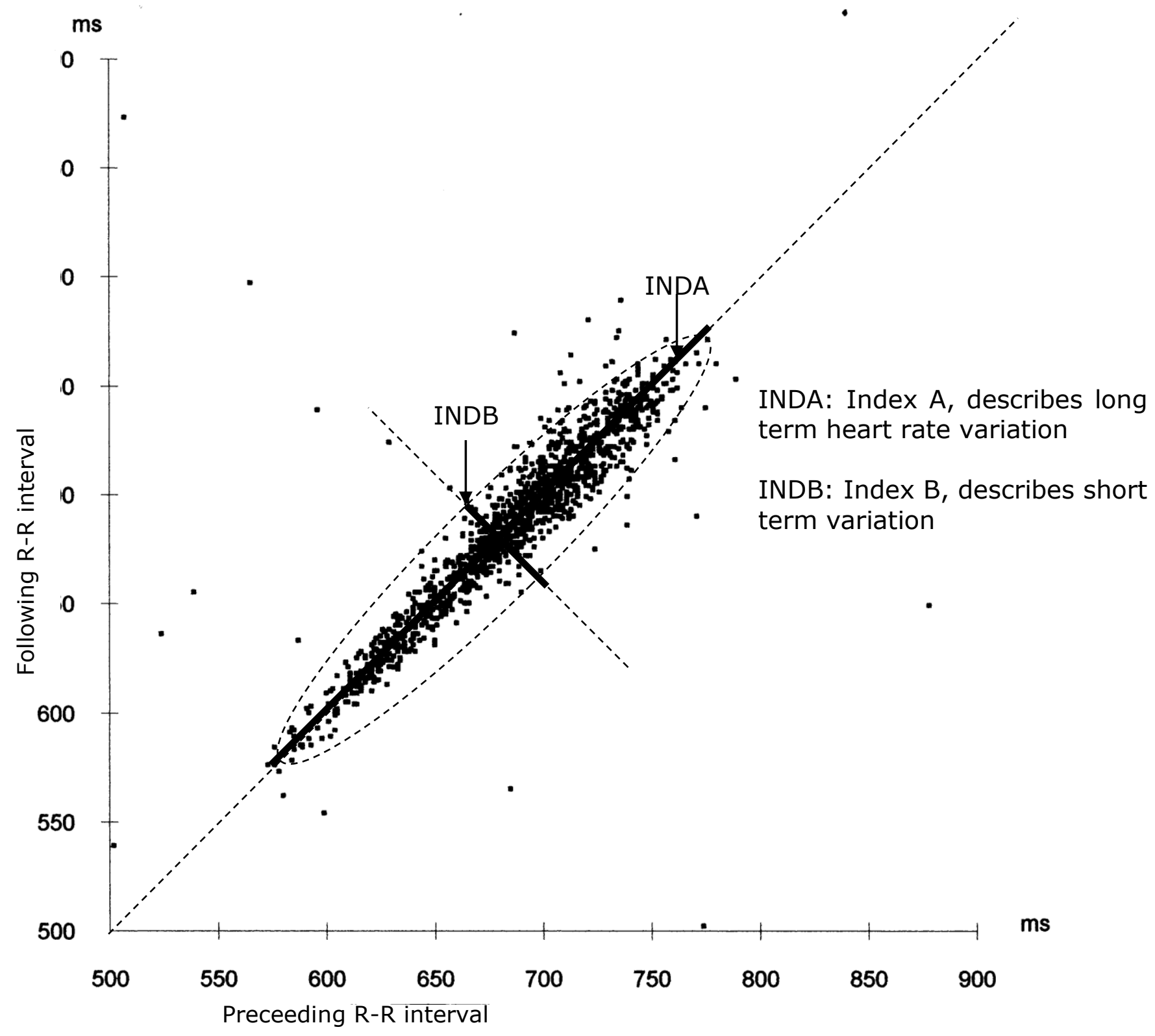

Fig.2: Poincaré plot used to illustrate heart beat rhythm and its changes in a cow. 